Open Access

Original Article

\title{
Percutaneous nephrolithotomy in new versus those patients with previous history of Extracorporeal Shock Wave Lithotripsy on ipsilateral side
}

\author{
Nadeem Iqbal ${ }^{1}$, Sajid Iqbal ${ }^{2}$, \\ Nasir Zareen ${ }^{3}$, Keron Akintola Ayodele Blair ${ }^{4}$
}

\section{ABSTRACT}

Objectives: To appraise the effects of previous history of ineffectual extracorporeal shockwave lithotripsy (SWL) treatment on the execution and end result of percutaneous nephrolithotomy (PCNL).

Methods: The study was performed from January 2012 till November 2019 at the urology department at our hospital, a tertiary healthcare center. In total, four hundred and twenty two patients were enrolled in the study. We arranged the study participants into two groups. Group-I comprised of 66 subjects who had undergone failed SWL 12 months prior to PCNL procedure, while Group-II included patients who had no history of previous SWL. Information related to study variables was registered in designated proformas and then processed in SPSS version 16 for the statistical computations.

Results: On the whole, the mean age of patients was $45.25 \pm 14.38$ years. While the mean calculus size was $494.80 \pm 128.83 \mathrm{~mm}^{2}$. The complexity of stones formulated on the basis of Guy's stone score was identical among the two groups. American Society of Anesthesiologists (ASA) class categories were almost similar among the two groups. Stone free rates of $80.30 \%$ and $81.74 \%$ ( $p$ value $=0.73$ ) were observed in Group-I and II respectively. Time to create PCNL tract and mean drop in hemoglobin were noted to be significantly higher in Group-I. Complication rates and grades were not being dissimilar among the two groups.

Conclusion: Patients having prior history of unsuccessful SWL history before undertaking the PCNL procedure manifested similar stone free rates and complications rates as those observed in SWL naive cases of PCNL.

KEYWORDS: PCNL, Stone Free Rates, Shock Wave Lithotripsy, Renal Stones, Complications.

doi: https://doi.org/10.12669/pjms.38.4.5116

How to cite this:

Iqbal N, Iqbal S, Zareen N, Blair KAA. Percutaneous nephrolithotomy in new versus those patients with previous history of Extracorporeal Shock Wave Lithotripsy on ipsilateral side. Pak J Med Sci. 2022;38(4):833-837. doi: https://doi.org/10.12669/pjms.38.4.5116

This is an Open Access article distributed under the terms of the Creative Commons Attribution License (http://creativecommons.org/licenses/by/3.0), which permits unrestricted use, distribution, and reproduction in any medium, provided the original work is properly cited.

1. Nadeem lqbal,

Shifa International Hospital, Islamabad, Pakistan.

INTRODUCTION

2. Sajid lqbal,

Department of Rehabilitation, Pakistan Navy PNS Hospital, Karachi, Pakistan.

3. Nasir Zareen,

SKBZ/CMH Rawlakot.

4. Keron Akintola Ayodele Blair,

American International School of Medicine, Georgetown Guyana.

Correspondence:

Dr. Nadeem Iqbal

Department of Urology and Kidney Transplant,

Pakistan Kidney Institute, Shifa International Hospital,

Sector $\mathrm{H}-8 / 4$, Islamabad, Pakistan.

E-mail: dr_nadeemiqbal84@yahoo.com

* Received for Publication:

* $1^{\text {st }}$ Revision Received:

* $2^{\text {nd }}$ Revision Received:

* Final Revision Accepted:
August 3, 2021

August 31, 2021

January 7, 2022

January 29, 2022

ESWL is benchmark treatment for smaller renal stones (size below $2 \mathrm{~cm}$ ). While PCNL is employed for larger calculi (complex and size more than 2 $\mathrm{cm}){ }^{1-4}$ The average cost of ESWL per treatment has made the procedure very much affordable to people with moderate income. ${ }^{4-6}$ This led to misuse of SWL in last few years especially in less developed regions and non academic hospitals. As indicated by the recent researches, some factors lead to lower stone free rates in patients having longer skin to stone distance, higher BMI, stone Hounsfield units and lower pole location. So, patients with history of previously failed 
SWL are encountered more frequently in urology practice nowadays. ${ }^{5,6}$

Repeated use of SWL contributes to changes such as fibrous degeneration and contortion of collecting system. ${ }^{7-12} \mathrm{Up}$ till now there are only few studies in literature that have thrown light on the ramifications of previous failed and frequent SWL procedures on the outcomes and complications of succeeding PCNL. Focus of present study was to share experience regarding the PCNL outcomes in those patients who had failed prior SWL sessions in a developing world country.

\section{METHODS}

The study was performed from January 2012 till November 2019 at the urology department at our hospital, after the approval of institutional review board and ethical committee (IRB\#936210-2017).

Patients showing features of congenital renal anomaly, ureteropelvic junction obstruction, age less than 18 years, those having abnormal coagulation profile, active urinary tract infection, and those who failed to come to come for follow up were excluded from the study. Additionally, those without CT scan studies prior to the PCNL procedure had to be excluded from the present study. Thus in total, four hundred and twenty two patients were enrolled in the study.
All patients undertook non-contrast CT scan for stones estimation preceding PCNL. Additionally, complete blood count, serum electrolytes, renal function tests, coagulation evaluation, urine routine analysis and culture tests, coagulation study were conducted. Stones complexity was allotted by utilization of Guy's stone score (GSS). Relevant antibiotic treatment with antibiotics was administered to patients, who were positive for bacterial colonies on urine cultures preoperatively. PCNL was executed by standard technique in the prone position.

PCNL procedure: Triangular or Bull's eye technique was utilized according to case to case. Lower pole was preferred to get an entry to the calyx. Contrast assisted opacification of collecting system was utilized to aid in having proper and safe entry of 18 $\mathrm{G}$ needle into the desired place within the kidney. Then over the wire, increasing size fascial dilators were utilized. Later on, Alken metallic dilators were pushed over the olive tip for tract creation. Following this, an Amplatz sheath (24-30 fr) was slid into the created tract and nephroscopy was carried out to locate and then retrieve the stones in the kidney. Pneumatic Lithoclast was applied for stone disintegration. Stone grasper (three-prong grasper) helped in stone retrieval. After that insertion of a 6 fr DJ stent was done in an antegrade fashion. The nephrostomy tube was secured with silk thread.

Table-I: Demographic variables.

\begin{tabular}{lccc}
\hline & Group-I (Previous history of SWL) & Group-II (No history of SWL) & P-value \\
\hline Number of patients & 66 & 356 & --- \\
Mean Age & $45.17 \pm 14.08$ years & $45.13 \pm 14.91$ years & 0.98 \\
Male & $44(66.6 \%)$ & $254(71.3 \%)$ & 0.463 \\
Female & $22(33.4 \%)$ & $102(28.6 \%)$ & \\
Right Renal stone & $27(40.9 \%)$ & $145(40.7 \%)$ & 0.97 \\
Left Renal stone & $39(59.1 \%)$ & $211(59.3 \%)$ & 0.057 \\
Body Mass Index & $27.79 \pm 3.39$ & $26.68 \pm 4.48$ & 0.086 \\
Mean stone size $\left(\mathrm{mm}^{2}\right)$ & $469.77 \pm 72.51 \mathrm{~mm}^{2}$ & $499.45 \pm 136.31 \mathrm{~mm}^{2}$ & \\
Guys Stone Score & & & \\
Guys Stone Score 1 & $32(48.48 \%)$ & $171(48.03 \%)$ & 0.46 \\
Guys Stone Score 2 & $23(34.84 \%)$ & $129(36.23 \%)$ & \\
Guys Stone Score 3 & $10(15.15 \%)$ & $38(10.67 \%)$ & \\
Guys Stone Score 4 & $1(1.51 \%)$ & $18(5.05 \%)$ & \\
ASA Class & & $274(76.96 \%)$ & \\
ASA Class 1 & $49(74.24 \%)$ & $67(18.82 \%)$ & \\
ASA Class 2 & $13(19.69 \%)$ & $15(4.21 \%)$ & \\
ASA Class 3 & $4(6.06 \%)$ & & \\
\hline
\end{tabular}


Percutaneous nephrolithotomy

Table-II: Details of Procedure Outcomes.

\begin{tabular}{lccc}
\hline & Group-I (Previous history of SWL) & Group-II (No history of SWL) & P-value \\
\hline Stone free rate & $53(80.30 \%)$ & $291(81.74 \%)$ & 0.73 \\
Residual stones & $13(19.69 \%)$ & $65(18.26 \%)$ & 0.73 \\
Mean Operative time & $139.21 \pm 56.86$ minutes & $134.83 \pm 71.18$ minutes & 0.63 \\
Number of tracts & $1.15 \pm 0.36$ & $1.11 \pm 0.31$ & 0.36 \\
Time to create tract & $13.12 \pm 4.99$ minutes & $11.49 \pm 3.86$ minutes & 0.003 \\
Nephrostomy tube & $43 / 66(65.15 \%)$ & $206 / 356(57.86 \%)$ & 0.46 \\
Drop in hemoglobin & $1.68 \pm 0.59 \mathrm{mg} / \mathrm{dl}$ & $1.42 \pm 0.85 \mathrm{mg} / \mathrm{dl}$ & 0.021 \\
Hospital stay & $2.94 \pm 0.79$ days & $2.99 \pm 1.27$ days & 0.77 \\
\hline
\end{tabular}

Follow up of Patients: At three months in outdoor clinic with help of Ultrasound and X-Ray KUB to look for status of any residual stones. The detection of residual fragments of size $\leq 4 \mathrm{~mm}$ or no fragments at all on radiology assessment was labelled as success of therapy.

Statistical Analysis: Analysis was achieved by utilizing SPSS version 16. Application of Mean along with standard deviation values was utilized in case of the continuous variables. While frequency/percentages portrayed categorical factors. We took help of independent student's t-test for comparing the continuous factors, while to weigh up categorical values between the groups, Chi-square test was utilized. A p value of $<0.05$ was judged as statistically crucial value.

\section{RESULTS}

In entirety 422 subjects were taken in the final analysis. Total of 66 patients were kept in Group-I that comprised of subjects having previous history of failed shock wave lithotripsy (SWL). While,
356 patients in Group-II were those who had no previous history of SWL. On the whole, the mean age of patients was $45.25 \pm 14.38$ years. While the mean calculus size was $494.80 \pm 128.83 \mathrm{~mm}^{2}$. The complexity of stones formulated on the basis of Guy's stone score was identical among the two groups (Table-I). The overall mean procedure time was almost 135 minutes and was not much dissimilar among the two groups (Table-II). Mean time for access to pelvicalyceal system was 13.12 \pm 4.99 minutes in Group-I as compared to $11.49 \pm 3.86$ minutes in Group-II (P value $=0.003$, Table-II). Stonefree rate was relatively higher among the SWL naïve patients (Group-II), however no significant difference was seen among the two groups in terms of stone free rates and residual stones.Table-II. Mean fall in hemoglobin was $1.68 \pm 0.59 \mathrm{mg} / \mathrm{dl}$ in first group in contrast to $1.42 \pm 0.85 \mathrm{mg} / \mathrm{dl}$ in second ( $\mathrm{p}$ value $=0.021$, Table-II) .

Complications were described in line with Clavien-Dindo Classification. Majority of the complications fell in Clavien-Grade-1. Major

Table-III: Complications.

\begin{tabular}{|c|c|c|c|c|}
\hline $\begin{array}{l}\text { Complication } \\
\text { Grade }^{*}\end{array}$ & Type Complication & Group-I & Group-II & p-value \\
\hline 1 & Fever & $5(7.57 \%)$ & $20(5.61 \%)$ & 0.56 \\
\hline 1 & Illeus & $2(3.03 \%)$ & $7(1.96 \%)$ & 0.63 \\
\hline 1 & Pelvicalyceal puncture (extravasation) & $2(3.03 \%)$ & $12(3.37 \%)$ & 1.0 \\
\hline 2 & Transfusion need & $4(6.06 \%)$ & $13(3.65 \%)$ & 0.31 \\
\hline 2 & Sepsis & $1(1.51 \%)$ & $5(1.40 \%)$ & 1.0 \\
\hline 3 & Perinephric abscess & $1(1.51 \%)$ & $2(0.56 \%)$ & 0.40 \\
\hline 3 & Iatrogenic bowel injury & $0 \%$ & $0 \%$ & --- \\
\hline 3 & Iatrogenic Renal vascular injury (angioembolisation) & $0 \%$ & $0 \%$ & \\
\hline 4 & Septic Shock (need for ICU management) & $0 \%$ & $1(0.28 \%)$ & 1.0 \\
\hline 5 & Death & $0 \%$ & $0 \%$ & --- \\
\hline
\end{tabular}

${ }^{*}$ Clavien-Dindo classification.

Pak J Med Sci $\quad$ March - April 2022 (Part-II) Vol. 38 No. $4 \quad$ www.pjms.org.pk 835 
complications such as iatrogenic renal vessel injury, or death were not encountered in any of the groups (Table-III).

\section{DISCUSSION}

Shock wave lithotripsy has fewer complications. The immediate common complications when they occur pertain to the mechanical damage from the shock wave. The shock wave can blow out the fragile arcuate veins proceeding to interstitial hemorrhage and hematoma formation. Apart from this, interstitial fibrosis occurs with segmental shrinkage of renal cortex. ${ }^{11-13}$ In addition to these changes, pressure waves (when ESWL procedures are applied frequently), can thrust the stone fragments in the neighborhood of renal mucosa. Yuruk et al. ${ }^{10}$ noted, shrank calyceal infundibulum and submerged stone chips underneath the pelvicalyceal mucosal layer in patients who earlier undertook sessions of failed SWL. Similarly, Wen Zhong et al found that Stone fragments submerged within renal tissue and narrowed calyceal infundibulum expanded the likelihood of residual stones after PCNL surgery. They had an inferior net stone clearance in the failed SWL group than in the patients who did not have antecedent intervention. ${ }^{11}$

Resorlu B et al. noticed no significant difference (in patients with antecedent open surgery or failed SWL history) regarding operative duration (minutes), time needed to acquire entrance to the renal collecting system, duration of fluoroscopy, adverse outcomes of PCNL and hospitalization duration. ${ }^{9}$ Yuruk E et al. observed comparable operative and fluoroscopic imaging duration in their study groups. ${ }^{10}$ Operative time was similar in two groups in the present study as well (TableII). They attained a success rate approximating $89 \%$. Their procedural success and frequency of complications were alike among the two groups. We had the similar success rates among the two groups (Table-II). They had increased operative and fluoroscopic imaging duration per $\mathrm{cm} 2$ of stone secondary to the tissue reaction of SWL and dispersed calculi fragments within the renal pelvicalyceal system.

Zhong $W$ et al. studied sixty-two patients (who had failed SWL history). The average duration between SWL and PCNL procedures approximated 6.48 months. ${ }^{11}$ They remarked that mean time to acquire a renal pelvicalyceal access was close among their groups (10.5 vs. 9.6 minutes). Similarly, the time needed to bring out renal stone was lengthened in the group who had prior history of failed SWL (71.5 vs. 62.3 minutes). In contrast to the observations made by Yuruk $\mathrm{E}$ et al. ${ }^{10}$ in another study done by Zhong $\mathrm{W}$ et al. ${ }^{11}$ it took significantly longer operative time in SWL failed group (95.8 vs. 80.6 minutes). They noticed inferior clearance of renal stones in group with failed SWL history (83.9\% versus $93.4 \%)$ which was statistically significant. We had similar success rate among both groups. In present study, the time to create access to pelvicalyceal system was significantly longer in Group-I (previous history of SWL) as compared to Group-II ( $p$ value $=0.003$, Table-II). Transfusion requirements were not dissimilar among their studied groups. ${ }^{11}$ Other complications including fever and peri-renal extravasation were not statistically significant. In present study, the complications were mostly Grade 1 and 2 and were similar across the two groups (Table-III).

Yesil S et al. observed higher frequency of renal vascular injury in subjects who had previous history of open renal stone procedures. ${ }^{14}$ In another study by Türk $\mathrm{H}$ et al, prior SWL procedures on the same side kidney did not impact attainment of PCNL success rate, operative time, frequency of adverse surgical outcomes and in hospital stay after surgery. ${ }^{15}$ Although, bleeding was usual in those patients who had previously undergone SWL for renal stones. Operative time and amount of bleeding tend to be higher owing to clinging of calculi fragments in scarred tissues of the renal pelvicalyceal system. ${ }^{16-18}$ Reddy SV et al. $^{19}$ mentioned that PCNL can be undertaken with safety in those who had prior surgical history including open stone surgery or PCNL. Avoidance of bumpy handling of nephroscope has a vital role in reducing the frequency of gross complications in patients who had previous open renal surgery. ${ }^{18-22}$ Retroperitoneal scarred tissue results in diminished kidney mobility, and reckless handling of nephroscope build a forceful torque that may result in renal lacerations and resultant bleed; at times even major vascular complications. ${ }^{18-22}$

Limitations: This study has few limitations such as a single center study and retrospective in nature. Number of patients having history of SWL was small. In previous studies stones were not categorized according to Guy's Stone scoring system, which we did. Guy's stone scores were similar between the two groups. Prospective multicenter studies have not been done regarding this subject. 


\section{CONCLUSION}

Those patients who have history of unsuccessful SWL before undertaking the PCNL procedure have almost similar stone free rates and frequency of complications as those observed in SWL naïve cases of PCNL. Moreover, prior history of unsuccessful SWL has no significant impact on operative time and hospital stay.

\section{Grant Support \& Financial Disclosures: None. \\ REFERENCES}

1. Temel MC, Ediz C, Okcelik S, Kiziloz H, Sariogullari U, Yilmaz O. Perioperative Indices Predicting Fever Following Percutaneus Nephrolithotomy. J Coll Physicians Surg Pak. 2020;30(12):1306-1311. doi: 10.29271/jcpsp.2020.12.1306

2. Malik HA, Tipu SA, Mohayuddin N, Sultan G, Hussain M, Hashmi A, et al. Comparison of holmium: Yag laser and pneumatic lithoclast in percutaneous nephrolithotomy. J Pak Med Assoc. 2007;57(8):385-387.

3. Shohab D, Iqbal N, Alam MU, Butt A, Jamil MI, Hussain I, et al. Comparison of Outcome of Percutaneous Nephrolithotomy in Adult Versus Paediatric Patients. J Coll Physicians Surg Pak. 2016;26:371-373.

4. Yang W, Cui Z, Ma T, Zhao C, Zhou H, Guo J. Effects of visual standard channel combined with visual superfine precision puncture channel or super-mini channel percutaneous nephrolithotomy on multiple renal calculi. Pak J Med Sci. 2018;34(3):535-539. doi: 10.12669/ pjms.343.14567

5. Celik S, Bozkurt O, Kaya FG, Egriboyun S, Demir O, Secil $\mathrm{M}$, Celebi I. Evaluation of computed tomography findings for success prediction after extracorporeal shock wave lithotripsy for urinary tract stone disease. Int Urol Nephrol. 2015;47:69-73. doi: 10.1007/s11255-014-0857-0

6. Iqbal N, Hasan A, Siddiqui FS, Iftikhar F, Siddiqui FS, Ilyas SM, et al. Outcome of percutaneous nephrolithotomy in preschool and school-age children-single center experience. J Ayub Med Coll Abbottabad. 2019;31:391-396.

7. Tugcu V, Su FE, Kalfazade N, Sahin S, Ozbay B, Tasci AI. Percutaneous nephrolithotomy (PCNL) in patients with previous open stone surgery. Int Urol Nephrol. 2008;4:881884. doi: $10.1007 /$ s11255-008-9376-1

8. Aquil S, Rana M, Zaidi Z. Laparoscopic assisted percutaneous nephrolithotomy (PCNL) in ectopic pelvic kidney. J Pak Med Assoc. 2006;56(8):381-383.

9. Resorlu B, Kara C, Senocak C, Cicekbilek I, Unsal A. Effect of previous open renal surgery and failed extracorporeal shockwave lithotripsy on the performance and outcomes of percutaneous nephrolithotomy. J Endourol. 2010;24:13-16. doi: 10.1089/end.2009.0291

10. Yuruk E, Tefekli A, Sari E, Karadag MA, Tepeler A, Binbay $\mathrm{M}$, et al. Does previous extracorporeal shock wave lithotripsy affect the performance and outcome of percutaneous nephrolithotomy? J Urol. 2009;181:663-667. doi: 10.1016/j. juro.2008.10.016

11. Zhong W, Gong T, Wang L, Zeng G, Wu W, Zhao Z, et al. Percutaneous nephrolithotomy for renal stones following failed extracorporeal shockwave lithotripsy: Different performances and morbidities. Urolithiasis. 2013;41:165-168. doi: $10.1007 /$ s00240-013-0545-z

12. Maxwell AD, Wang YN, Kreider W, Cunitz BW, Starr F, Lee D, et al. Evaluation of Renal Stone Comminution and Injury by Burst Wave Lithotripsy in a Pig Model. J Endourol. 2019;33:787-792. doi: 10.1089/end.2018.0886
13. Handa RK, Territo PR, Blomgren PM, Persohn SA, Lin C, Johnson CD, et al. Development of a novel magnetic resonance imaging acquisition and analysis workflow for the quantification of shock wave lithotripsy-induced renal hemorrhagic injury. Urolithiasis. 2017;45(5):507-513. doi: 10.1007/s00240-016-0959-5

14. Yesil S, Ozturk U, Goktug HN, Tuygun C, Nalbant I, Imamoglu MA. Previous open renal surgery increased vascular complications in percutaneous nephrolithotomy (PCNL) compared with primary and secondary PCNL and extracorporeal shock wave lithotripsy patients: A retrospective study. Urol Int. 2013;91:331-334. doi: 10.1159/000351968

15. Turk H, Yoldas M, Suelozgen T, Isoglu CS, Karabicak M, Ergani B, et al. Effects of previous unsuccessful extracorporeal shockwave lithotripsy treatment on the performance and outcome of percutaneous nephrolithotomy. Arab J Urol. 2017;15:94-99. doi: 10.1016/j.aju.2017.01.009

16. Mungan NA, Simsek AR, Tok A, Aliskan T, Cicekbilek I, Yavuzalp O, et al. The effects of time period after open stone surgery and ESWL to the success rate of percutaneous nephrolithotomy. Turkiye Klinikleri J Urol. 2014;5:39-45.

17. Yang L, Lu S, Han X, Wei P, Yang J, Hao T. Clinical comparison of the efficiency and security of balloon dilators versus fascial dilators in percutaneous nephrolithotripsy (PCNL). Pak J Med Sci. 2016;32(3):635-640. doi: 10.12669/ pjms.323.9281

18. May PC, Kreider W, Maxwell AD, Wang YN, Cunitz BW, Blomgren PM, et al. Detection and Evaluation of Renal Injury in Burst Wave Lithotripsy Using Ultrasound and Magnetic Resonance Imaging. J Endourol. 2017;31:786-792. doi: 10.1089/end.2017.0202

19. Reddy SV, Shaik AB. Outcome and complications of percutaneous nephrolithotomy as primary versus secondary procedure for renal calculi. Int Braz J Urol. 2016;42:262-269. doi: 10.1590/S1677- 5538.IBJU.2014.0619

20. Labate G, Modi P, Timoney A, Cormio L, Zhang X, Louie $\mathrm{M}$, et al. Rosette on Behalf of The Croes PCNL Study Group J. The percutaneous nephrolithotomy global study: classification of complications. J Endourol. 2011;25:1275-1280. doi: 10.1089/end.2011.0067

21. $\mathrm{Hu} \mathrm{H,} \mathrm{Lu} \mathrm{Y,} \mathrm{Cui} \mathrm{L,} \mathrm{Zhang} \mathrm{J,} \mathrm{Zhao} \mathrm{Z,} \mathrm{Qin} \mathrm{B,} \mathrm{et} \mathrm{al.} \mathrm{Impact}$ of previous open renal surgery on the outcomes of subsequent percutaneous nephrolithotomy: A meta-analysis. BMJ Open. 2016;6:e010627. doi: 10.1136/bmjopen-2015-010627

22. El-Assmy A, Harraz AM, Eldemerdash Y, Elkhamesy M, El-Nahas AR, Elshal AM, et al. Does lithotripsy increase stone recurrence? A comparative study between extracorporeal shockwave lithotripsy and non-fragmenting percutaneous nephrolithotomy. Arab J Urol. 2016;14:108-114. doi: 10.1016/j.aju.2016.02.004

\section{Authors' Contribution:}

NI, SI: Conceived, designed and did statistical analysis \& editing of manuscript, is responsible for integrity of research.

NI, SI, NZ, AKA: Did data collection and manuscript writing.

NI, NZ, AKA: Did review and final approval of manuscript.

NI: Author responsible for accuracy or integrity of the work. 